\title{
CUIDADO E DIREITOS FUNDAMENTAIS: 0 CASO DO HABEAS CORPUS COLETIVO PARA PAIS E RESPONSÁVEIS POR CRIANÇAS E PESSOAS COM DEFICIÊNCIA
}

\author{
CARE AND FUNDAMENTAL RIGHTS THE CASE OF THE COLLECTIVE HABEAS CORPUS FOR \\ PARENTS AND CAREERS OF CHILDREN AND PERSONS WITH DISABILITIES
}

\author{
Bruna Angotti ${ }^{1}$ \\ Regina Stela Corrêa Vieira² \\ Robison Tramontina ${ }^{3}$
}

\begin{abstract}
Resumo: No presente estudo de caso analisamos o Habeas Corpus 165.704 DF, voltado a todas as pessoas em situação de prisão e que têm sob sua única responsabilidade deficientes e crianças. A concessão da ordem foi proferida pela Segunda Turma do Supremo Tribunal Federal (STF) em 20 de outubro de 2020, ampliando o entendimento da decisão do Habeas Corpus 143.641 SP que concedeu a substituição da prisão preventiva por domiciliar em favor de todas as mulheres submetidas à prisão cautelar, que fossem gestantes, puérperas ou mães com crianças de até 12 anos de idade e de pessoas com deficiência, salvo algumas exceções. Este caso merece ser estudado justamente por alargar o entendimento de que não apenas mães são responsáveis pelo cuidado de seus filhos, reconhecendo outras pessoas como cuidadoras principais, portanto, rompendo com a tradicional divisão sexual do trabalho. Tal discussão, urgente e necessária, deve também ser aprofundada em outras áreas, adquire especial relevância em tempos da pandemia da Covid-19, nos quais foram exacerbadas as tarefas do cuidado.

Palavras-chave: Direitos fundamentais. Habeas Corpus 165.704 DF. Habeas Corpus 143.641 SP. Cuidado.
\end{abstract}

\begin{abstract}
In the present case study, we analyze Habeas Corpus 165.704 DF, aimed at all people who are in prison and are responsible for disabled and children. The order was granted by the Supreme Federal Court (STF) on October 20, 2020, expanding the understanding of the decision of Habeas Corpus 143.641 SP that granted, with some exceptions, the substitution of pre trial detention for home prison in favor of all women who were pregnant or mothers to children up to 12 years of age and people with disabilities. This case deserves to be studied precisely because it broadens the understanding that not only mothers are responsible for the care of their children, recognizing other people as primary caregivers, therefore, breaking with the traditional sexual division of labor. This discussion, which is urgent and must also be deepened in other areas, acquires special relevance in times of the Covid-19 pandemic, in which care tasks were exacerbated.
\end{abstract}

Keywords: Fundamental Rights. Habeas Corpus 165.704 DF. Habeas Corpus 143.641 SP. Care.

Recebido em 27 de outubro de 2020 Aceito em 28 de outubro de 2020

\footnotetext{
Doutora e Mestre em Antropologia Social pela Universidade de São Paulo; Vice-coordenadora do Núcleo de Antropologia do Direito; Professora na graduação em Direito da Universidade Presbiteriana Mackenzie; https://orcid.org/0000-00027894-5341; angotti.bruna@gmail.com

2 Doutora e Mestre em Direito pela Universidade de São Paulo; Professora no Programa de Pós-Graduação em Direito da Universidade do Oeste de Santa Catarina; Nereu Ramos, 3777-D, Bairro Seminário, 89813-000, Chapecó, Santa Catarina, Brasil; https://orcid.org/0000-0002-4407-4867; regina.vieira@unoesc.edu.br

3 Doutor e Mestre em Filosofia pela Pontifícia Universidade Católica do Rio Grande do Sul; Professor e Coordenador no Programa de Pós-Graduação em Direito da Universidade do Oeste de Santa Catarina; https://orcid.org/0000-0002-18524983; robison.tramontina@unoesc.edu.br.
} 


\section{Introdução}

A temática do cuidado é uma questão-chave para diversos ramos do Direito, sendo uma perspectiva possível para a interpretação e aplicação jurídica (VIEIRA, 2018). No ano de 2020, em razão da pandemia da Covid-19, tal questão tornou-se incontornável. Falar de cuidado, das pessoas responsáveis por cuidar de si e de outras, bem como daquelas que demandam cuidados em diversos âmbitos da vida pública e privada, converteu-se em obrigação política, moral e epistemológica.

Apesar das origens sanitárias, os efeitos da pandemia desdobraram-se em diversas esferas da vida social, com reflexos na economia, no mundo do trabalho, chegando inclusive à esfera doméstica. A pressão sobre os sistemas de saúde gerou a necessidade de medidas governamentais rápidas para a redução do contágio, em face a uma doença com evolução e tratamento desconhecidos. A única resposta possível foi o isolamento social (WORLD HEALTH ORGANIZATION, 2020) e a paralização de diversos setores da atividade econômica, sendo permitido o funcionamento apenas de atividades essenciais, como serviços de saúde, mercados, indústrias de alimentos e de produtos de limpeza.

Desde o início da propagação dos casos de Covid-19 no Brasil, acadêmicos, operadores do Direito e organizações de direitos humanos têm alertado sobre o alto índice de contágio dentro das prisões, dada a já conhecida superlotação do sistema prisional que impede a implantação das medidas de distanciamento e o fato de esta população ser mais vulnerável ao vírus devido a comorbidades e outras doenças infectocontagiosas. ${ }^{4}$ Medidas concretas foram tomadas na tentativa de minimizar os danos da doença. Para além de ações individuais de advogados e defensores, caso a caso, tentando garantir a saída de seus clientes da prisão, houve esforços voltados a grupos específicos que poderiam ser beneficiados por medidas desencarceradoras coletivas.

Nesse sentido, diversos Habeas Corpus coletivos ${ }^{5}$ foram impetrados nos Tribunais de Justiça estaduais, no Superior Tribunal de Justiça e no Supremo Tribunal Federal visando a liberdade provisória ou aplicação de medidas cautelares alternativas à prisão. Presos pertencentes ao grupo de risco - como gestantes, pessoas imunodeprimidas e idosos - principais responsáveis pelo cuidado de vulneráveis durante a pandemia, incluindo integrantes do grupo de risco, crianças e pessoas com deficiência, foram os pacientes-alvo dessas medidas coletivas. Foi notório o esforço de defensorias públicas, estaduais e da União, e de coletivos de advogados e organizações do terceiro setor voltado para isso.

\footnotetext{
4 Por exemplo, mesmo com o limitado acesso a diagnóstico clínico, a incidência de HIV na população carcerária é 138 vezes maior que a observada na população geral e, de tuberculose, 49 vezes maior (DEPARTAMENTO PENITENCIÁRIO NACIONAL DO MINISTÉRIO DA JUSTIÇA E SEGURANÇA PÚBLICA, 2016).

5 Por exemplo o HC 596.189, voltado para pessoas presas do grupo de risco da Covid-19; o HC 575.495 MG, que teve como pacientes presos do regime semiaberto, que foram impedidos de sair da prisão para trabalhar durante a pandemia; o HC570.440 DF em favor de pessoas presas ou daquelas que que eventualmente venham a ser presas e são pertencentes ao grupo de risco; e o HC 0052186-97 RJ em favor de todas as pessoas presas cuidadoras principais de pessoas do grupo de risco da Covid-19, do qual duas das autoras do presente estudo de caso foram subescritoras, juntamente com outras advogadas e advogados do Coletivo de Advocacia em Direitos Humanos (CADHu).
} 
Nesse contexto, o objetivo deste trabalho é analisar a decisão proferida pela Segunda Turma do Supremo Tribunal Federal (STF) em 20 de outubro de 2020, em sede do Habeas Corpus 165.704 DF, impetrado pelo estudante de direito Julio Cesar Carminati Simões, e que, por decisão do STF, tem como polo ativo a Defensoria Pública da União, tendo como pacientes todas as pessoas que se encontram presas e que têm sob sua única responsabilidade deficientes e crianças.

O caso analisado é relevante para o estudo dos direitos humanos e fundamentais, tendo em vista abordar situações concretas de proteção de direitos fundamentais relacionados ao cuidado e à saúde. À luz dessa ação coletiva bem sucedida, em meio a uma série de negativas a Habeas Corpus com objetos similares, pretende-se dar destaque ao fato de que reivindicações por direitos fundamentais de grupos, postas em diálogo com a jurisprudência e articulados com a melhor técnica jurídica, podem trazer benefícios e estender garantias a uma ampla gama de sujeitos, cujo aprisionamento acarreta ruptura com laços familiares e uma série de violações extramuros.

\section{Os fatos}

O Habeas Corpus 165.704 DF foi impetrado diretamente no Supremo Tribunal Federal por serem autoridades coatoras os juízes das Varas criminais estaduais, Tribunais de Justiça dos Estados e do Distrito Federal, juízes federais com competência criminal, Tribunais Regionais Federais e o Superior Tribunal de Justiça. Logo, não haveria instância inferior ao STF competente para julgar o caso, nos termos do art. 650, I do Código de Processo Penal.

Por buscar garantias a uma coletividade de pacientes que integra o sistema carcerário estadual e federal em oposição às autoridades coautoras supramencionadas, a eleição do instrumento coletivo e das razões e embasamento jurídico para o pedido tomaram como base o precedente julgado no Habeas Corpus 143.641 SP. Impetrado pelo Coletivo de Advocacia em Direitos Humanos - CADHu, em 8 de maio de 2017, o referido instrumento requereu a substituição da prisão preventiva por domiciliar em favor de todas as mulheres submetidas à prisão cautelar, que fossem gestantes, puérperas ou mães com crianças de até 12 anos de idade e de pessoas com deficiência.

O referido Habeas Corpus coletivo foi um exemplo bem sucedido de litigância estratégica, porquanto houve a confluência entre argumentos jurídicos precisos e um momento propício, dado que em abril do mesmo ano fora proferida decisão da $7^{\text {a }}$ Vara Criminal Federal do Rio de Janeiro que concedeu prisão domiciliar à Adriana Ancelmo, esposa do ex-governador Sérgio Cabral, à época acusada de crimes de corrupção e lavagem de dinheiro (POMPEU, 2018). A decisão, amplamente veiculada pela mídia e debatida pela sociedade civil, tinha com argumento central a tese da necessidade da presença materna para o desenvolvimento de seus dois filhos menores (11 e 14 anos), em razão da ausência do pai, que também estava preso (STJ - HC 383.606).

○ writ coletivo tomou como base jurídica a alteração promovida pelo Marco Legal da Primeira Infância (Lei 13.257/2016) no art. 318 do Código de Processo Penal, cuja redação passou a 
ser: "Art. 318. Poderá o juiz substituir a prisão preventiva pela domiciliar quando o agente for: [...] IV - gestante; V - mulher com filho de até 12 (doze) anos de idade incompletos." A lei previa uma prática que os tribunais pouco cumpriam, sendo a via escolhida pelo CADHu para buscar garantir a prática da previsão legal aquela do Habeas Corpus coletivo. Considerou-se no pedido que quando a violação de direitos é coletiva, o remédio para saná-la também o deve ser, inaugurando, assim, tese inovadora ao sustentar um pedido feito a pacientes inominadas pertencentes a uma coletividade não identificada por falha do Estado na produção de dados sobre o sistema prisional e seus internos.

Assim, o argumento partiu da constatação de que tais previsões legais voltadas ao desencarceramento das mulheres futura ou imediatamente responsáveis pelo cuidado de seus filhos não estavam sendo aplicadas na prática por grande parte dos magistrados brasileiros. A natureza coletiva do Habeas Corpus deveu-se à abrangência, generalização e ao caráter sistêmico do problema, visando a ganhar amplitude necessária à cessação das lesões aos direitos fundamentais dessas mulheres, crianças e pessoas com deficiência. Afinal, "se a violação a direitos é massiva, o remédio há de ser coletivo." (HC 0052186-97.2020.8.19.0000 - TJRJ).

Em 20 de fevereiro de 2018, poucos dias depois do caso de Jéssica Monteiro ter ganhado repercussão - ela foi presa em flagrante com $90 \mathrm{~g}$ de maconha aos 9 meses de gestação, e dias depois sua imagem atrás das grades com o filho recém-nascido nos braços foi veiculada em jornais e na TV -, a Segunda Turma do STF julgou e concedeu a ordem ao HC 143.641 SP, para que mulheres presas provisoriamente e adolescentes internadas que estivessem grávidas ou fossem mães de filhos de até 12 anos tivessem o direito à prisão domiciliar (FRAGOSO et. al., 2019, p. 26).

Na decisão histórica de 2018, quedou reforçado o entendimento do próprio Supremo Tribunal Federal na Ação de Descumprimento de Preceito Fundamental 347 (ADPF), na qual reconheceu que o sistema carcerário brasileiro se encontra em um "estado de coisas inconstitucional", sendo necessária a atuação estatal para mitigação do quadro. Para a efetivação do julgado, foi determinada busca-ativa ao Departamento Penitenciário Nacional (DEPEN) requerendo o levantamento das mulheres que haviam sido beneficiadas pelo $\mathrm{HC}$.

Ademais, em 19 de dezembro do mesmo ano, foi sancionada a Lei 13.769/2018, que incluiu no Código de Processo Penal certos pontos tratados na decisão do HC coletivo, a fim de estabelecer a substituição da preventiva por prisão domiciliar da mulher gestante ou que for mãe ou responsável por crianças ou pessoas com deficiência, além de disciplinar o regime de cumprimento de pena privativa de liberdade de condenadas na mesma situação.

No entanto, apesar de tais conquistas representarem passos significativos para solução concreta de casos de violação de direitos fundamentais, deixaram de considerar pessoas responsáveis primordiais pelo cuidado de vulneráveis que não necessariamente mães, como pais e outros familiares de acordo com o arranjo familiar. Disso decorreu a pergunta que fundamentou o Habeas Corpus 165.704 DF, conforme consta na exordial: "qual é a legalidade, frente ao art. 5, I, CF/88, da manutenção da prisão sem a conversão em domiciliar para homens ou qualquer pessoa que seja a 
única responsável pela criança ou deficiente, considerando que está já fora permitida às mulheres, no HC 143641?" (SIMÕES, 2018).

Assim, o fato considerado relevante para impetrar o $\mathrm{HC}$ objeto deste estudo é de que nem todas as crianças e pessoas com deficiência que necessitam de cuidados o recebem de uma mãe, havendo uma gama diversa de pessoas que podem assumir a responsabilidade principal pelo cuidado deste indivíduo. Além disso, não somente famílias monoparentais possuem apenas um responsável pela manutenção da casa e da família. Nesse sentido, a inicial cita notícia de um pai que foi preso por "pescar para comer" em local de proteção ambiental em Vitória, Espirito Santo, buscando garantir que sua esposa e filho se alimentassem.

Segundo informações do Conselho Nacional de Justiça (CNJ), apresentadas nos autos do processo a pedido do relator, Ministro Gilmar Mendes, o número de presos responsáveis por crianças ou pessoas deficientes era de 31.841 pessoas (BRASIL, 2020, p. 3). ${ }^{6}$ Conforme a própria Defensoria Pública da União explicou nos autos, ainda que nem todo esse montante seja de pessoas em prisão cautelar, o número é expressivo, ainda mais considerando o considerável percentual de presos provisórios no país (BRASIL, 2020, p. 3).

Somou-se a esse contexto factual a situação de pandemia do coronavírus, de maneira que em 21 de março de 2020 a Defensoria Pública da União (DPU) protocolou petição reiterando os pedidos formulados e reforçando a urgência de que HC coletivo fosse julgado, tendo em vista:

a) a necessidade de se garantir a permanência das crianças com seus responsáveis durante esse período de quarentena e isolamento social; b) a possibilidade de se reduzir o número da população carcerária com base em critério razoável e constitucionalmente sustentado (melhor interesse da criança), de modo inclusive a diminuir os riscos de infecção pelo Covid-19 em um sistema prisional abarrotado; c) as recentes proibições de visitas implementadas no âmbito do sistema penitenciário, o que pode acarretar no afastamento das crianças em relação a seus responsáveis por tempo ainda maior. (BRASIL, 2020, p. 4).

Em torno desses fatos debruçou-se o julgamento ora em análise, com uma história processual que, apesar de bastante linear, revelou-se peculiar devido à impetração do Habeas Corpus ter partido de um estudante de Direito, então no $5^{\circ}$ período da faculdade. Detalharemos como o caso chegou ao STF e os atos processuais mais significativos no item a seguir.

\footnotetext{
6 Não tivemos acesso ao Ofício n 278/GP/2019, protocolado em 3 de abril de 2019, no qual o CNJ presta tais informações a pedido do Ministro-relator. Por isso, não sabemos como elas foram coletadas e se, de fato, abarcam todas as pessoas cuidadoras principais de crianças e pessoas com deficiência. Com base na manifestação da DPU a esses dados, sabemos apenas que eles não separam presos provisórios e condenados em definitivo.
} 


\section{História processual}

Diferente do Habeas Corpus 143.641 SP, que integra um histórico de litigância estratégica do CADHu, o já mencionado coletivo de advogadas e advogados ativistas da defesa dos Direitos Humanos, ancorados em relevantes pesquisas sobre maternidade no cárcere (CF. BRAGA; ANGOTTI, 2019), o HC 165.704 DF foi impetrado por Julio Cesar Carminati Simões, individualmente.?

O estudante de Direito, na época com 21 anos e cursando o $3^{\circ}$ ano da Faculdade Doctum de Guarapari, no Espírito Santo, afirma ter lido o acórdão do HC coletivo referente à substituição da prisão preventiva pela domiciliar para todas as gestantes e mães de crianças com até 12 anos ou de pessoas com deficiência e sentido "um desconforto". Em reportagem para o Portal Jota, Simões diz que notou que "a decisão era omissa na questão dos outros responsáveis", tendo visto ali "uma possibilidade jurídica da ampliação dos efeitos da ordem" (RIBAS, 2020).

Em 27 de novembro de 2018, o Habeas Corpus foi impetrado e, logo que distribuído, o relator, Ministro Gilmar Mendes, encaminhou os autos à Presidência do STF, para análise de eventual prevenção em relação ao HC no 143.641/SP. O então Presidente do Supremo, Dias Toffoli, entendeu não haver vínculo específico entre os processos em questão, não caracterizando a prevenção do relator do caso anterior, Ricardo Lewandowski. Dessa forma, foi mantida a livre distribuição e, consequentemente, a relatoria do Ministro Gilmar Mendes (BRASIL, 2020).

Com o retorno dos autos ao Ministro-relator, o mesmo proferiu despacho em 14 de fevereiro de 2019, intimando a Defensoria Pública da União (DPU) a manifestar seu interesse em ingressar no polo ativo da referida ação, entendendo que o autor não possuía legitimidade para a impetrar o HC coletivo. Interessante frisar que esta decisão monocrática embasou-se, mais uma vez, em precedente fixado no HC no 143.641 SP, no qual a Segunda Turma do STF entendeu que o CADHu não era legítimo para integrar o polo ativo do writ relativo às presas gestantes e mães de crianças pequenas ou com deficiência, por ser ela reservada aos atores listados no art. 12 da Lei 13.300/2016. Diante disso, reconheceu-se a legitimidade ativa da DPU e os impetrantes foram admitidos como seus assistentes (BRASIL, 2018).

No caso em estudo, o Defensor Público Geral Federal manifestou-se requerendo o ingresso no polo ativo do writ. Assim, em despacho de 9 e abril de 2019, o Ministro-relator admitiu o ingresso da Defensoria Pública da União no polo ativo da ação, tornando o estudante Julio Cesar Carminati Simões amicus curiae. Posteriormente, a DPU apresentou novas informações e manifestou-se sobre os dados apresentados pelo CNJ sobre o caso. Além disso, a Procuradoria-Geral da República manifestou-se, em 3 de setembro de 2019 pela concessão da ordem (BRASIL, 2020).

\footnotetext{
7 Aproveitamos a oportunidade para agradecer ao próprio Julio Cesar Carminati Simões, a quem contatamos via Instagram, solicitando a petição por ele redigida para HC coletivo, que não estava disponível no sistema eletrônico do STF. Ele nos respondeu prontamente e mandou a peça por e-mail, a qual foi aqui referenciada como Simões (2018).
} 
A última manifestação nos autos antes da decisão, ocorrida em março de 2020, foi a já transcrita no item 2 deste estudo de caso, na qual a Defensoria Pública da União reiterou os pedidos formulados no $\mathrm{HC}$ e destacou a premência do julgamento devido à pandemia do Covid-19 e seus reflexos quanto ao aumento da vulnerabilidade de crianças, pessoas com deficiência e, também, das pessoas que se encontravam no sistema carcerário.

\section{0 direito}

O Habeas Corpus 165.704 DF, ora em estudo, foi impetrado em favor de "todas as pessoas que se encontram presas e que têm sob a sua única responsabilidade deficientes e crianças", requerendo que a decisão proferida nos autos do Habeas Corpus 143.641 SP, em favor de todas as mulheres presas preventivamente, gestantes ou mães de crianças de até 12 anos ou de pessoas com deficiência, "deveria ter seu alcance estendido a todas as pessoas que se encontram presas e que têm sob sua única responsabilidade deficientes e crianças, pelas mesmas razões e fundamentos." (BRASIL, 2020).

Sustentou o impetrante que ao tutelar direitos de crianças e pessoas com deficiência filhas de mães presas, acabou por discriminar aquelas que dependem de cuidados providos por outros responsáveis, ferindo, portanto, o princípio constitucional da igualdade (BRASIL, 2020). Sendo assim, a manutenção do encarceramento provisório desse cuidador ou dessa cuidadora principal violaria sua própria dignidade, criaria "graves consequências" para as crianças menores de 12 anos em desenvolvimento, e transgrediria "o direito do deficiente em ter um acompanhamento social e familiar de alguém de sua confiança." (BRASIL, 2020).

Portanto, o objetivo de proteção de crianças e pessoas com deficiência cujos responsáveis encontravam-se encarcerados era o que assemelhava o writ em questão ao precedente firmado no julgamento do Habeas Corpus 143.641 SP. Neste último, porém, como o pedido formulado restringiuse à figura materna, não foi "realizada a análise de outros laços constituídos por crianças e outras pessoas responsáveis, como pais, avós, tios e irmãos." (BRASIL, 2020).

A exordial, ancorada no precedente mencionado, faz referência à Lei 13.257/2016, ou Marco Legal da Primeira Infância, citando as mudanças por ela inseridas no art. 318 do Código de Processo Penal. No referido artigo, passou-se a permitir que o juiz substitua a prisão preventiva pela domiciliar quando o agente for gestante (inciso IV), mulher com filho de até 12 anos de idade (inciso V) ou homem, caso seja o único responsável pelos cuidados do filho de até 12 anos de idade (inciso VI). Desse modo, a alteração legislativa contemplou não apenas as mulheres, mas também homens cuidadores principais.

Argumenta, então, que "a negativa da conversão da prisão preventiva em domiciliar não fere apenas o direito subjetivo do agente, mas 'leva à pique' todo um ordenamento jurídico, no qual, a proteção à família é tutelada." (SIMÕES, 2018). Assim, defende que o art. 318 do CPP protege não a pessoa encarcerada, mas a criança ou pessoa com deficiência que dele dependa. Seu argumento é reforçado pelo 
art. 17 da Convenção Americana dos Direitos Humanos, que trata justamente da proteção da família, e se encerra com a conclamação do princípio da dignidade humana (SIMÕES, 2018).

Encerra evocando novamente o princípio da igualdade presente no art. 5 I da Constituição, afirmando que os pais e qualquer outro responsável único pelo cuidado de criança ou pessoa com deficiência deveriam ser abraçados pela possibilidade da conversão da prisão preventiva em domiciliar, não apenas as mulheres-mães (SIMÕES, 2018). Em conclusão, sustenta que "o mínimo ético exigido do Estado, após a excessiva punição do indivíduo mantido preso [cautelarmente, havendo morosidade na investigação ou instrução criminal] e por conseguinte, aqueles que dele dependam, é a conversão para a prisão domiciliar." (SIMÕES, 2018).

\section{Razões fáticas e jurídicas da decisão final}

Em decisão unânime, a Segunda Turma do Supremo Tribunal Federal concedeu a ordem ao Habeas Corpus 165.704 DF, determinando a substituição da prisão cautelar por domiciliar de pais e responsáveis por crianças menores de 12 anos ou pessoas com deficiência, cumpridos os requisitos do art. 318 do CPP e outras condicionantes elencadas na ementa final, descrita no item a seguir.

Os Ministros que integram a Segunda Turma, Edson Fachin, Cármen Lúcia e Ricardo Lewandowski, acompanharam o relator, Ministro Gilmar Mendes. Por isso, analisaremos o voto deste último, a fim de destacar as principais razões fáticas e jurídicas articuladas na decisão do caso aqui estudado.

O Ministro-relator inicia seu voto mencionando o precedente, votado pela mesma Turma do STF em 2018. De acordo com ele, a decisão do HC 143.641 SP destacou que "o exame do direito à prisão domiciliar deveria ser realizado sob a ótica do melhor interesse das crianças ou dos portadores de deficiência." (BRASIL, 2020, p. 10). Com base nessa compreensão é que o caso em debate, envolvendo laços constituídos com outros responsáveis, deveria ser analisado (BRASIL, 2020, p. 11).

Segundo o Ministro Gilmar Mendes, sob o ponto de vista jurídico e penal, apesar de a Constituição proibir a transferência da pena da pessoa condenada a outrem, conforme art. $5^{\circ}, \mathrm{XLV}$, as "consequências extrajurídicas, econômicas e sociais impostas às famílias" das pessoas presas, especialmente aos seus filhos menores, podem ser muito graves." (BRASIL, 2020, p. 11).

Ademais, continua citando o art. 227 da Constituição, que prevê ser

dever da família, da sociedade e do Estado assegurar à criança, ao adolescente e ao jovem, com absoluta prioridade, o direito à vida, à saúde, à alimentação, à educação, ao lazer, à profissionalização, à cultura, à dignidade, ao respeito, à liberdade e à convivência familiar e comunitária, além de colocá-los a salvo de toda forma de negligência, discriminação, exploração, violência, crueldade e opressão. (BRASIL, 1988). 
Além da doutrina da proteção integral a crianças e adolescentes, segundo o relator, também as pessoas com deficiência merecem especial proteção nos termos da inicial do HC em debate, que destaca o art. $7^{\circ}$ e 23 da Convenção Internacional das Pessoas com Deficiência, que falam na obrigação dos Estados de garantirem às crianças com deficiência o pleno exercício dos direitos humanos, bem como a necessidade de assegurar que não sejam separadas de seus pais, a não ser que esteja ancorada em determinação de autoridades competentes.

$\mathrm{Na}$ sequência, volta suas considerações ao art. 318 do Código de Processo Penal, destacando que "o inciso III do art. 318 do CPP determina a concessão da prisão domiciliar da pessoa responsável por esses indivíduos, independentemente do nível de parentesco", e que o inciso IV fala especificamente de presos do sexo masculino, aos quais pode ser concedida a prisão domiciliar desde que ele seja o único responsável pelo cuidado dos filhos (BRASIL, 2020, p. 14).

Aprofundando o debate em torno de tal artigo, o Ministro Gilmar Mendes passa a argumentar que é preciso compreender a ratio dessa previsão legal. Nas suas palavras:

Apesar de beneficiar os presos responsáveis por crianças e pessoas com deficiência, é preciso entender que, antes de qualquer coisa, o dispositivo tutela os nascituros, as crianças e os portadores de deficiência que, em detrimento da proteção integral e da prioridade absoluta que lhes confere a ordem jurídica brasileira e internacional, são afastados do convívio de seus pais ou entes queridos, logo em uma fase da vida em que se definem importantes traços de personalidade. (BRASIL, 2020, p. 14).

Para corroborar seu argumento, o Relator retoma o precedente do HC143.641 SP, citando trecho do voto do Ministro Ricardo Lewandowski em que apresenta estudos de Harvard que demonstrariam que a privação de suporte psicológico e de afeto na infância prejudica o desenvolvimento da criança. O Ministro Gilmar Mendes também cita decisão liminar proferida por ele em outro Habeas Corpus, na qual concedeu prisão domiciliar à mãe de uma criança de quatro anos, "que passou a sofrer alteração comportamental e dificuldades de alimentação, com diagnóstico médico de episódio depressivo moderado, após a separação do convívio com sua genitora." (BRASIL, 2020, p. 16).

Como argumento final, o Relator enfatiza que "a situação de risco e urgência na concessão da ordem é reforçada pela atual situação de pandemia mundial e proliferação do Coronavírus (Covid-19) no Brasil." (BRASIL, 2020, p. 16). Nesse sentido, faz alusão à Resolução 60/2020 do Conselho Nacional de Justiça, com recomendações de medidas preventivas referentes à Covid-19 a serem adotadas por juízes e tribunais em todo o país, voltadas inclusive, ao sistema penitenciário brasileiro. Dentre as medidas da Resolução, consta a recomendação aos magistrados que reavaliem prisões provisórias, priorizando "mulheres gestantes, lactantes, mães ou pessoas responsáveis por criança de até doze anos ou por pessoa com deficiência, assim como idosos, indígenas, pessoas com deficiência ou que se enquadrem no grupo de risco" (art. $\left.4^{\circ}, \mathrm{I}\right)$.

Conclui o Relator que a "não concessão da prisão domiciliar na situação de calamidade de saúde em que vivemos pode gerar ainda mais consequências negativas", pois o prolongamento do 
isolamento social como medida para evitar o contágio da Covid-19 pode "contribuir para a consolidação dos danosos efeitos decorrentes da separação dessas pessoas dos seus responsáveis." (BRASIL, 2020, p. 18-19). Ele justifica sua conclusão apresentando dados sobre a suspensão das visitas a presos durante a pandemia e de que a manutenção dessas pessoas no regime fechado pode colocar em risco sua saúde, em face ao "estado de coisas inconstitucional" reconhecido na ADPF 347, bem como à constatação de se tratar de "ambiente insalubre e de propagação de doenças", conforme constatado no Relatório da CPI da Câmara Federal sobre o sistema penitenciário (BRASIL, 2020, p. 19).

A síntese das razões fáticas e jurídicas apresentadas no voto do Ministro Gilmar Mendes ele mesmo apresenta:

Em síntese, tendo em vista a proteção integral e a prioridade absoluta conferidas pela Carta de 1988 às crianças e aos portadores de deficiência, julgo que a substituição da preventiva pela domiciliar, nos casos dos incisos III e VI do art. 318 do CPP, deva ser a regra, em especial nas atuais circunstâncias de grave crise na saúde pública nacional que geram riscos mais elevados às pessoas inseridas no sistema penitenciário.

A exceção, ou seja, a recusa à substituição, deve ser amplamente fundamentada pelo magistrado, e só deve ocorrer em casos graves, tais como a prática de crime com violência ou grave ameaça à pessoa. Ademais, não faria sentido que o agente fosse beneficiado pela substituição quando pese contra ele prática de crimes contra a sua prole.

Ressalte-se que o art. 318, inciso VI, do CPP, prevê expressamente que nos casos de presos do sexo masculino, o juiz deverá substituir a prisão preventiva pela domiciliar caso ele seja o único responsável pelos cuidados do filho de até 12 (doze) anos de idade incompletos.

Em caso de outras pessoas presas que não sejam a mãe ou o pai, o inciso III estabelece que deverá o juiz substituir a prisão preventiva pela domiciliar se o preso for imprescindível aos cuidados especiais de pessoa menor de 6 (seis) anos de idade ou com deficiência.

Portanto, tais parâmetros devem ser observados no cumprimento da ordem. Devem ser igualmente observados os critérios estabelecidos no precedente firmado no HC 143.641 e na Recomendação no 62/2020 do CNJ. (BRASIL, 2020, p. 23).

\section{A tese firmada na decisão final}

A decisão relativa ao Habeas Corpus 165.704 DF, publicada em 20 de outubro de 2020, concedeu a ordem nos seguintes termos:

Decisão: A Turma, por votação unânime, conheceu e concedeu a ordem de habeas corpus coletivo, para determinar a substituição da prisão cautelar dos pais e responsáveis por crianças menores e pessoas com deficiência, desde que observadas as seguintes condicionantes: (i) presença de prova dos requisitos do art. 318 do CPP, o que poderá ser realizado inclusive através de audiência em caso de dúvida sobre a prova documental carreada aos autos; (ii) em caso de concessão da ordem para pais, que haja a demonstração de que se trata do único responsável pelos cuidados do menor de 12 (doze) anos ou de pessoa com deficiência, nos termos acima descritos; (iii) em caso de concessão para outros responsáveis que não sejam a mãe ou o pai, a comprovação de que se trata de pessoa imprescindível aos cuidados especiais de pessoa menor de 6 (seis) anos de idade ou com deficiência; 
(iv) a submissão aos mesmos condicionamentos enunciados no julgamento do HC n 143.641/SP, especialmente no que se refere à vedação da substituição da prisão preventiva pela segregação domiciliar em casos de crimes praticados mediante violência ou grave ameaça, ou contra os próprios filhos ou dependentes; (v) a concessão da ordem, em caráter emergencial, nos casos elencados na Recomendação n 62/2020 do CNJ, para substituição da prisão preventiva por domiciliar ou concessão de saída antecipada do regime fechado ou semiaberto, nos termos da Súmula Vinculante 56 desta Corte; (vi) a comunicação da ordem ao DMF para acompanhamento da execução; (vii) a expedição de ofício a todos os Tribunais de Justiça e Tribunais Regionais Federais, com cópia desta decisão, para que comuniquem a esta Corte os casos de concessão de habeas corpus com base neste julgamento, no prazo de 45 (quarenta e cinco) dias. Prosseguindo, a Turma determinou que com a chegada das informações, haja a reavaliação das medidas de fiscalização e monitoramento necessárias ao cumprimento do acórdão, na forma acima descrita, nos termos do voto do Relator. Falou, pelos pacientes, o Dr. Gustavo de Almeida Ribeiro, Defensor Público da União e, pelo Ministério Público Federal, o Dr. José Elaeres Marques Teixeira. Presidência do Ministro Gilmar Mendes. $2^{\text {a }}$ Turma, 20.10.2020. (BRASIL, 2020).

Prevaleceu, portanto, a compreensão já firmada no precedente HC 143.641 SP, de que o direito à prisão domiciliar, seja de mães, pais ou de outros responsáveis, deve ser analisado sob a ótica do melhor interesse das crianças menores de 12 anos ou de pessoas com deficiência que demandam cuidados advindos da pessoa presa preventiva/cautelarmente.

\section{Crítica}

O cuidado é a atividade multidimensional da qual depende a continuidade da vida humana. Todas as pessoas recebem cuidado e o exercem com maior ou menor intensidade ao longo da vida, de modo que a vulnerabilidade e a necessidade de conexão fazem parte da nossa constituição (CARRASCO; BORDERÍAS; TORNS, 2011). Algumas fases da vida ou determinadas condições trazem maiores graus de dependência, sendo notórios os casos de crianças pequenas e pessoas com deficiência. $^{8}$

A provisão de cuidado no Brasil é majoritariamente realizada dentro das casas, por pessoas da família - do total de 168,7 milhões de pessoas em idade de trabalhar em 2017, 31,5\% (ou 53,2 milhões de pessoas) realizaram cuidados de moradores do domicilio ou de parentes não moradores, segundo dados do $\operatorname{IBGE}(2018$, p. 5). Em tempos de pandemia, as responsabilidades e cargas relacionadas ao cuidado aumentaram, ${ }^{9}$ tendo também ganhado maior visibilidade, pois nunca foi tão premente a higienização dos ambientes e dos corpos, as atividades de manutenção dos lares e a atenção às pessoas próximas (Cf. NICOLI; VIEIRA, 2020).

\footnotetext{
8 Ressalva-se a pluralidade das pessoas com deficiência. Muitas são plenamente independentes, outras precisam de cuidados pontuais e, outras ainda, dependem na presença de outras pessoas para atividades essenciais. Elas podem, inclusive, necessitarem de cuidado em determinados momentos e, em outros, constituírem-se cuidadoras (FIETZ; MELLO, 2018).

9 Segundo pesquisa realizada pela organização Gênero e Número e pela SOF - Sempreviva Organização Feminista, 50\% das mulheres brasileiras passaram a cuidar de alguém na pandemia da Covid-19 (BIANCONI et al., 2020).
} 
O encarceramento não tira a responsabilidade pelo cuidado que recai sobre pessoa em situação de prisão, tampouco soluciona a necessidade de receber cuidado de quem está a ela vinculado. Logo, vemos como acertado o embasamento da decisão aqui analisada levar em conta tanto as garantias da pessoa presa provisoriamente, incluindo seu direito fundamental à saúde, quanto a proteção integral de crianças e pessoas com deficiência, pela qual passa respeitar a demanda por cuidado. Esse cuidado, como explica a teoria feminista, deve ser considerado em termos multidimensionais, englobando desde o fornecimento de alimentação e higienização corporal até o respeito aos laços afetivos entre os envolvidos na relação (HIRATA; DEBERT, 2016).

O caso ganha relevo por ter conseguido ampliar o entendimento firmado no precedente, HC 143.641 SP. A garantia de prisão domiciliar a presas provisórias gestantes e mães de crianças de até 12 anos ou de pessoas com deficiência foi uma conquista jurídica muito relevante, interferindo diretamente no cotidiano de milhares de mulheres e garantindo a convivência familiar entre estas e seus filhos/as. Ainda assim, sua ampliação a pais e outros responsáveis era fundamental, o que foi conquistado no julgamento do HC 165.704 DF.

Para além de corrigir a exclusão de crianças e de pessoas com deficiência cujo cuidador principal é o pai ou outro responsável, o caso analisado pode ser considerado um passo no sentido da incorporação da crítica feminista do Direito na jurisprudência. Afinal, a igualdade de gênero pressupõe igualdade de papéis e o compartilhamento das tarefas produtivas e reprodutivas, de modo que normas jurídicas e decisões que reforcem o lugar materno, ainda que tenham a intenção válida de proteger a saúde das mães e garantir o cuidado aos filhos, acabam por reforçar o papel socialmente atribuído às mulheres de cuidadoras. Com isso, reproduz-se em âmbito jurídico a divisão sexual do trabalho, cobrando as mães e isentando os pais das responsabilidades com crianças (ANGOTTI; VIEIRA, 2020).

Vale dizer que a expansão das garantias relacionadas ao cuidado para as mães e crianças para pais ou outros responsáveis, vista no caso analisado, não foi a precursora. Isso já ocorreu, por exemplo, na inserção dos art. 392-B e art. 392-C da CLT, decorrente da Lei 12.873/2013, passando a prever que pais poderiam ser beneficiários de licença-maternidade em caso de morte da genitora, bem como mães ou pais adotivos, independente do sexo ou do arranjo familiar em que estão inseridos.

Em face a isso, bem como à previsão do reiteradamente citado art. 318 do CPP, o que surpreende é o fato de juízes e tribunais não aplicarem a conversão da prisão preventiva/cautelar em domiciliar para qualquer caso em que o preso tenha responsabilidades essenciais no cuidado de pessoa vulnerável, tendo o Supremo Tribunal Federal que se manifestar sobre o tema para que a previsão legal fosse efetivada. Ainda mais em um momento de crise sanitária, diante de normativas do CNJ conclamando a execução de medidas que retirassem da prisão pessoas que poderiam migrar para a domiciliar ou progredir de regime.

Além disso, destacamos que a falta de dados precisos sobre quem pode ser beneficiário faz com que não tenhamos noção da quantidade exata de pessoas que será beneficiada pela medida , 
afinal, não há o registro de quantas pessoas e quem são as pessoas em situação de cárcere que são cuidadores principais de crianças e pessoas com deficiência, separado. É fundamental que o sistema tenha esse olhar, de entender o entorno da pessoa de maneira mais detalhada logo no seu ingresso, uma vez que tais dados podem, inclusive, embasar políticas públicas. Portanto, o mapeamento das pessoas que estão no sistema prisional deveria ser mais efetivo e integral, a fim de registrar os efeitos de cada aprisionamento extramuros, justamente para que seja considerada a concessão dos benefícios.

Em face ao exposto neste estudo de caso, podemos afirmar que o HC 165.704 DF é uma evolução incremental de um sistema de garantias conferidas aos provedores de cuidado a partir de construção jurisprudencial, cuja trajetória tem como marco o HC 143.641 SP, fruto do esforço de litigância estratégica do CADHu. Esperamos, portanto, que mais esta acertada decisão da Segunda Turma do Supremo Tribunal Federal acarrete na imediata soltura dos pacientes beneficiários, bem como paute outras ações e decisões que visem ao alargamento da atribuição social da função do cuidado.

\section{REFERÊNCIAS}

ANGOTTI, Bruna; VIEIRA, Regina Stela Corrêa. Da reprodução à função social: o papel do direito no reforço do lugar materno. In: SEVERI, F. C.; CASTILHO, E. W. V. de; MATOS, M. C. Direitos Humanos das Mulheres e Violências. Ribeirão Preto: Editora FDRP, 2020. (no prelo).

BIANCONI, Giuliana et al. Sem parar: o trabalho e a vida das mulheres na pandemia. São Paulo: Gênero e Número e SOF - Sempreviva Organização Feminista, 2020. Disponível em: http://mulheresnapandemia.sof.org.br/. Acesso em: 23 out. 2020.

BRAGA, Ana Gabriela Mendes; ANGOTTI, Bruna. Dar à luz na sombra - Condições atuais e possibilidades futuras para o exercício da maternidade por mulheres em situação de prisão. São Paulo: Editora Unesp, 2019.

BRASIL. Constituição. República Federativa do Brasil de 1988. Brasília, DF: Senado Federal, 5 out. 1988.

BRASIL. Supremo Tribunal Federal (2. Turma). Habeas Corpus 143.641 SP. Relator: Ricardo Lewandowski. Julgamento em 24 de outubro de 2018. Brasília, DF, 2018. Disponível em: http://portal.stf. jus.br/processos/detalhe.asp?.incidente $=5183497$. Acesso em 20 out. 2020.

BRASIL. Supremo Tribunal Federal (2. Turma). Habeas Corpus 165.704 DF. Órgão Julgador: Segunda Turma. Relator: Gilmar Mendes. Julgamento em 20 de outubro de 2020. Brasília, DF, 2020. Disponível em: http://portal.stf.jus.br/processos/detalhe.asp?incidente $=5596542$. Acesso em 20 out. 2020.

CARRASCO, Cristina; BORDERÍAS, Cristina; TORNS, Teresa (ed.). El trabajo de cuidados: historia, teoría y políticas. Madrid: Catarata, 2011.

DEPARTAMENTO PENITENCIÁRIO NACIONAL DO MINISTÉRIO DA JUSTIÇA E SEGURANÇA PÚBLICA. Levantamento nacional de informações penitenciárias: INFOPEN. Brasília: Ministério da Justiça e da Segurança Pública, 2016. 
FIETZ, Helena Moura; MELLO, Anahi Guedes de. A Multiplicidade do Cuidado na Experiência da Deficiência. Revista Anthropológicas, v. 22, n. 2, p. 114-141, 2018.

FRAGOSO, Nathalie et al. Pela liberdade: a história do habeas corpus coletivo para mães \& crianças. São Paulo: Instituto Alana, 2019.

HIRATA, Helena; DEBERT, Guita Grin. Apresentação. Cadernos Pagu, v. 46, p. 7-15, jan./abr. 2016.

IBGE. Outras formas de trabalho 2017. PNAD Contínua. Rio de Janeiro: IBGE, 2018.

NICOLI, Pedro Augusto Gravatá; VIEIRA, Regina Stela Corrêa. Cuidado em surto: da crise ética. Revista Cult, ano 23, ed. 257, p. 74-77, maio 2020.

POMPEU, Ana. STJ confirma prisão domiciliar de ex-primeira-dama Adriana Ancelmo. Consultor Jurídico, 27 fev. 2018. Disponível em: https://www.conjur.com.br/2018-fev-27/stj-confirma-prisao-domiciliar-ex-primeira-dama-adriana-ancelmo. Acesso em: 20 out. 2020.

RIBAS, Mariana. Estudante impetrou HC em que STF concedeu domiciliar a responsáveis por crianças. JOTA, 22 out. 2020. Disponível em: https://www.jota.info/stf/do-supremo/hc-estudante-stf-22102020. Acesso em: 23 out. 2020.

SIMÕES, Julio Cesar Carminati. Petição inicial. Habeas Corpus 165.704 DF. Órgão Julgador: Segunda Turma. Relator: Gilmar Mendes. Impetrado em 27 de novembro de 2018. Distrito Federal, 2018.

VIEIRA, Regina Stela Corrêa. O cuidado como trabalho: uma interpelação do Direito do Trabalho a partir da perspectiva de gênero. 2018. Tese (Doutorado em Direito) - Faculdade de Direito, Universidade de São Paulo, São Paulo, 2018.

WORLD HEALTH ORGANIZATION. COVID-19: physical distancing. Geneva: WHO, 2020. Disponível em: https://www.who.int/westernpacific/emergencies/covid-19/information/physical-distancing. Acesso em: 28 set. 2020. 